\title{
Hypoxia-Inducible Factor-1 $\alpha$ Dependent Pathways Mediate the Renoprotective Role of Acetazolamide Against Renal Ischemia-Reperfusion Injury
}

\author{
Yu An ${ }^{a, b}$ Jian-zhao Zhanga, Jing Han ${ }^{a, b}$ Hao-peng Yang ${ }^{a, b}$ Lu Tie ${ }^{a, b}$ \\ Xiao-yuan Yang ${ }^{b}$ Yilixiati Xiaokaitia ${ }^{a, b}$ Pan Pan ${ }^{a, b} \quad$ Xue-jun Lia,b \\ aState Key Laboratory of Natural \& Biomimetic Drugs, Department of Pharmacology,

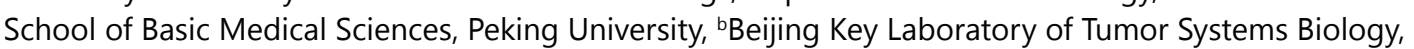 \\ Peking University, Beijing, China
}

\section{Key Words}

Acute kidney injury - Kidney transplantation - Ischemia reperfusion - Acetazolamide • Hypoxia-inducible factor- $1 \alpha$

\begin{abstract}
Background/Aims: Acute kidney injury (AKI) is a major complication of kidney transplantation, resulting in early graft dysfunction. Since diuretic acetazolamide (AZA) has been shown to improve contrast induced AKI, we hypothesized that AZA also protected against ischemiareperfusion (I/R) caused AKI. Methods: An in vivo mouse renal I/R injury model and an in vitro $\mathrm{H}_{2} \mathrm{O}_{2}$ stimulated $\mathrm{HK}-2$ cell injury model were utilized to examine the renoprotective effect of AZA. Renal injury and blood flow were measured. Nitric oxide synthase (eNOS)/Nitric oxide (NO), cell apoptosis and hypoxia-inducible factor- $1 \alpha$ (HIF-1 $\alpha$ ) changes were analyzed. Results: AZA reduced kidney injury scores and improved renal function by decreasing serum creatinine and BUN levels after I/R. Impaired renal blood flow was restored by increasing eNOS activities and NO production, as indicated by Laser Doppler imaging. TUNEL staining presented that AZA reduced apoptotic cells due to attenuated caspase activation and increased $\mathrm{BCl}-2 /$ Bax ratio. Furthermore, HIF-1 $\alpha$ induction by AZA was demonstrated. AZA also enhanced in vitro NO production, reduced cell apoptosis and increased HIF-1 $\alpha$ expression. Knockdown of HIF-1 $\alpha$ by RNAi confirmed that AZA exerted its protective role depending on HIF- $1 \alpha$. AZA's effects were significantly reduced by Akt inhibitor LY294002. Conclusions: The present study demonstrated that AZA exerted a renoprotective role against I/R induced AKI through activating HIF- $1 \alpha$ and downstream pathways.
\end{abstract}




\section{Cellular Physiology and Biochemistry}

Cell Physiol Biochem 2013;32:1151-1166 \begin{tabular}{l|l}
\hline DOI: $10.1159 / 000354515$ & (c) 2013 S. Karger AG, Basel
\end{tabular}

Publisned onlIne: November 11, $2013 \quad$ www.karger.com/cpb

An et al.: AZA Ameliorates Renal I/R Injury via HIF-1a

\section{Introduction}

Acute kidney injury (AKI) has long been a severe threat to kidney disease patients [14]. Among various factors inducing the disorder, renal ischemia-reperfusion (I/R) injury is considered the leading cause [5,6]. With respect to the inevitable association between kidney transplantation and ischemia followed by reperfusion, patients receiving kidney transplantation tend to be diagnosed with early graft dysfunction due to I/R induced AKI [7, 8]. After ischemic insult and during reperfusion, renal tubular cells sustain oxidative injury resulting in cell apoptosis and necrosis, partially due to impairment of renal blood flow [9]. Therefore, pharmacologically restoring renal blood flow and interfering apoptotic cell death are regarded as effective strategies to improve renal I/R injury.

There have been reports about the improvement of renal I/R injury through regulating the hypoxia-inducible factor- $1 \alpha$ (HIF-1 $\alpha$ ), which is a key transcriptional factor mediating cellular adaptation under stress conditions including I/R injury via an array of protective genes involved in the process of cell metabolism, angiogenesis, erythropoiesis and antiapoptosis [10]. It has been well documented that HIF-1 $\alpha$ plays a crucial role in ameliorating I/R injury in different organs, such as brain [11], heart [12], liver [13] and kidney [14]. Therefore, pharmacological methods to regulate HIF-1 $\alpha$ are intensively pursued.

Acetazolamide (AZA) is prescribed to treat edema related diseases such as glaucoma and high mountain sickness. AZA has been reported to effectively induce vessel dilation including the renal circulating system [15]. Moreover, administration of AZA could exert a renoprotective role against contrast induced AKI clinically $[16,17]$. The possible protective mechanism has been linked to alkalinizing the renal tubular fluid by AZA and then increased scavenge of contrast induced reactive oxygen species. The other explanation is vasodilation effect of AZA may ameliorate contrast caused vasoconstriction and regional hypoxia $[15,18]$. However, a renoprotective role of AZA against I/R injury has not been tested.

In the present study, AZA was found to improve renal function in a murine I/R model in vivo and prevent human kidney-2 (HK-2) cell death in vitro. AZA also restored renal blood flow by activating the eNOS/NO production and reduced cell apoptosis via up-regulating the ratio of Bcl-2/Bax, both in an HIF-1 $\alpha$ dependent manner.

\section{Materials and Methods}

Ethics Statement

This study was performed in strict accordance with the recommendations in the Guide for the Care and Use of Laboratory Animals of China Association for Laboratory Animal Science. All animal care and experimental protocols were approved by the Animal Care Committee of Peking University Health Science Center. All sacrifice was performed under pentobarbitone anesthesia, and every effort was made to minimize suffering.

\section{Agents}

Acetazolamide and LY294002 were from Sigma-Aldrich Corporation (St. Louis, MO, USA). Anti HIF$1 \alpha$ (BS3514), Bcl-2 (BS1511), Bax (BS2538), Actived-Caspase-3 (BS7004) and PTEN (BS1305) primary antibodies were from Bioworld Technology, Inc. (Louis Park, MN, USA). Primary antibodies to PI3K p85 (\#4257), Akt (\#9272), p-Akt (Ser473,\#4060), mTOR (\#2983), p-mTOR (Ser2448,\#5536), ERK1/2 (\#4695), p-ERK1/2 (Thr202/Tyr204, \#4370) and p-eNOS (Ser1177, \#9570) were obtained from Cell Signaling Technology, Inc. (Danvers, MA, USA). Anti eNOS (sc-654) and anti PI3K p-p85 (sc-12929) primary antibodies were bought from Santa Cruz Biotechnology, Inc. (Santa Cruz, CA, USA). Unless specifically indicated, all the other biochemical reagents were obtained from Amresco (Solon, OH, USA).

Experimental animals and renal ischemia-reperfusion model

Male C57BL/6j mice at ages of 12 weeks weighing 20-22g were obtained from Animal Center at Peking University Health Science Center (Beijing, China). Renal ischemia-reperfusion (I/R) injury was induced 


\section{Cellular Physiology and Biochemistry}

Cell Physiol Biochem 2013;32:1151-1166

\begin{tabular}{l|l}
\hline DOI: $10.1159 / 000354515$ & (C) 2013 S. Karger AG, Basel
\end{tabular}

www.karger.com/cpb

An et al.: AZA Ameliorates Renal I/R Injury via HIF-1a

under pentobarbital $(80 \mathrm{mg} / \mathrm{kg})$ anesthesia as previously described [19]. Briefly, mice were divided into 3 groups: sham, I/R model and AZA treated group with a dose of $60 \mathrm{mg} / \mathrm{kg} /$ day, with 6 mice per group. For I/R insult, left renal artery and vein underwent ligation with a non-traumatic clamp for 30 minutes, then the clamp was released to cause reperfusion, which lasted for 48 hours. In sham group, the same operation was performed without renal vessels occlusion. Mice in AZA treated group was administrated orally with $60 \mathrm{mg} / \mathrm{kg} /$ day acetazolamide solution for two consecutive days before ischemia insult and during $48 \mathrm{~h}$ of reperfusion, while corresponding vehicle was given to mice in either sham group or I/R model group. In addition, all underwent right nephrectomy operation and during the operations body temperature was maintained at $37^{\circ} \mathrm{C}$ by a homoeothermic blanket. Systemic blood pressure, the main electrolytes $\mathrm{Na}^{+}$and $\mathrm{K}^{+}$concentrations in plasma and urine were also monitored by a noninvasively operating blood pressure analyzer (BP-2000, Visitech Systems Inc., USA) and an automatic analyzer (Johnson \& Johnson Clinical Diagnostics, Rochester, NY, USA), respectively.

\section{Renal function test}

Renal function was measured by 2 common parameters: serum creatinine and blood urea nitrogen (BUN) [20], which were both determined by commercial kits (Cayman Chemical Company, Ann Arbor, USA). Serum collected from mice was utilized to measure both 2 parameters according to the manufacturer's instructions.

\section{Hematoxylin-eosin and TUNEL staining}

Mice kidney paraffin-embedded sections at $4 \mu \mathrm{m}$ were stained with hematoxylin and eosin. After images (200× magnification) were recorded, histomorphological injury scoring of renal tissue damage was analyzed by observing loss of epithelial cells brush border, dilation of tubules, casts production and tubular necrosis as described previously $[21,22]$. The scoring grades were determined by a double-blind observer as follows: 0 , normal; 1 , damage less than $25 \%$; 2 , damage between $25 \%$ and $50 \%$; 3 , damage between $50 \%$ and $75 \%$; 4amage more than 75\%. For each animal, at least 6 independent images were collected for observation and statistical analysis. At least 3 fields in each image were analyzed for histomorphological injury scoring.

The kidney sections were also assayed for apoptosis measurement by using a commercial in situ celldeath detection kit (G3250, Promega, Madison, USA), based on terminal deoxynucleotidyl transferase biotindUTP nick end labeling (TUNEL) staining according to the manufacturer's instructions. TUNEL-positive cells, which were counted for quantification, were indicated in green and/or orange (overlay) fluorescence in Figures 3A, 3E and 4K.

\section{Laser Doppler perfusion imaging}

Renal blood flow was measured by using a Laser Doppler perfusion imager (MoorLDI, Moor Instruments Ltd, Devon, UK) before ischemia insult (0), after $30 \mathrm{~min}$ of ischemia (30 $\mathrm{min}$ ) and after $48 \mathrm{~h}$ of reperfusion (48h). Relative measurement of blood flow was expressed in arbitrary perfusion units (PU). The recorded images were analyzed using corresponding MoorLDI v2.1 software (Moor Instruments Ltd, Devon, UK) and the perfusion value was taken and divided by the baseline measurement to give a percentage representing the relative blood flow changes.

\section{Cell culture and $\mathrm{H}_{2} \mathrm{O}_{2}$ stimulation}

Human kidney-2 (HK-2) cell line was from Cell Culture Center, Institute of Basic Medical Science, Chinese Academy of Medical Sciences (Beijing, China). Briefly, HK-2 cells were cultured in DMEM/F12 medium supplemented with antibiotics (penicillin and streptomycin) and 10\% fetal bovine serum (FBS; Hyclone, Logan, Utah, USA) in a humid atmosphere incubator with $5 \% \mathrm{CO}_{2}$ at $37^{\circ} \mathrm{C}$. The cells were treated with drugs or vehicle after growing to $70 \%$ to $80 \%$ confluence. For $\mathrm{H}_{2} \mathrm{O}_{2}$ stimulation, $\mathrm{HK}-2$ cells were stimulated with $500 \mu \mathrm{mol} / \mathrm{L}$ for 8 hours to induce in vitro proximal tubular epithelial cells injury as described before [19].

\section{Nitric oxide measurement}

The nitric oxide level was measured via a commercial NO (nitric oxide) assay kit (Beyotime, Haimen, China) as described previously [23]. Briefly, after homogenizing frozen mice kidneys in a buffer containing protease inhibitors and centrifugation, the supernatant was used for NO measurement. For HK-2 cells, the 


\section{Cellular Physiology and Biochemistry}

Cell Physiol Biochem 2013;32:1151-1166

\begin{tabular}{l|l}
\hline DOI: $10.1159 / 000354515$ & (C) 2013 S. Karger AG, Basel
\end{tabular}

www.karger.com/cpb

An et al.: AZA Ameliorates Renal I/R Injury via HIF-1 $\alpha$

culture medium was collected for testing NO levels. After incubation with reagents in the assay kit according to the manufacturer's instructions, the absorbance at $540 \mathrm{~nm}$ was measured with a microplate reader (Thermo Scientific, Menlo Park, CA, USA). The concentrations of NO were calculated following instructions of the kit.

Cell viability assay

Cell viability was measured through a commercial MTS assay kit (Promega, Fitchburg, Wisconsin, USA). After reagent in this assay kit was added for 4 hours in each well, the absorbance at $490 \mathrm{~nm}$ was determined by a microplate reader (Thermo Scientific, Menlo Park, CA, USA).

HIF-1 $\alpha$ RNAi assay

Commercial HIF-1 $\alpha$ siRNA (sc-35561) and negative control scramble siRNA (sc-37007) were obtained from Santa Cruz Biotechnology, Inc. (Santa Cruz, CA, USA). Briefly, HIF-1 $\alpha$ or scramble siRNA at a concentration of $100 \mathrm{nmol} / \mathrm{L}$ was transiently transfected into HK-2 cells through Lipofectamine-2000 reagent (Invitrogen, Carlsbad, CA, USA) according to the manufacturer's instructions, respectively. After incubation with HIF-1 $\alpha$ or scramble siRNA for 72 hours, HK-2 cells were harvested for further examination.

Immunoblot analysis

After frozen mice kidney tissues were homogenized and HK-2 cells were harvested, they were lysed in RIPA buffer containing PMSF (phenylmethylsulfonyl fluoride) and protease inhibitor cocktail (Calbiochem, San Diego, CA, USA). Following centrifugation at $12,000 \mathrm{~g}$ for $15 \mathrm{~min}$ at $4^{\circ} \mathrm{C}$, the supernatants were collected and protein content was measured by the bicinchoninic acid (BCA) assay kit (Thermo Scientific Pierce, Rockford, IL, USA).Briefly, samples $(80 \mu \mathrm{g})$ were separated by $12 \%$ sodium dodecyl sulfate-polyacrylamide gel (SDS-PAGE). Upon completion of the electrophoresis, the proteins were transferred to PVDF membrane. Non-specific binding sites were blocked by pre-incubating the membrane in $5 \%$ skimmed milk in Trisbuffered saline Tween (TBS-T, 20mmol/L Tris, $137 \mathrm{mmol} / \mathrm{L} \mathrm{NaCl}, \mathrm{pH}$ 7.6). PVDF membranes were then incubated overnight at $4{ }^{\circ} \mathrm{C}$ with specific primary antibodies. After washing three times with TBS-T buffer, the membranes were incubated with the appropriate horseradish-peroxidase (HRP)-conjugated secondary antibody (Santa Cruz Biotechnology, Santa Cruz, CA, USA), blots were developed by using Western Blotting Luminol Reagent (Santa Cruz Biotechnology, Santa Cruz, CA, USA). Then the western blot bands were scanned, and bands intensity was analyzed by Bio-Rad Quantity One software (version 4.4.0; Bio-Rad, Hercules, CA, USA) for quantification.

Data and statistical Analysis

All results are expressed as means \pm S.E.M. For multiple comparisons, the statistical analysis was performed by using one-way analysis of variance (ANOVA) followed by the Newman-Keuls multiple comparison tests. $P<0.05$ was considered statistically significant.

\section{Results}

\section{Effects of acetazolamide on renal histomorphology and function}

To investigate whether AZA could exert an in vivo renoprotective effect, C57BL/6j mice were subjected to sham operation (sham group), or ischemia/reperfusion with treatment of saline (I/R group) or $60 \mathrm{mg} / \mathrm{kg} /$ day AZA (AZA group). Kidney sections in the I/R group stained with hematoxylin-eosin presented plenty of injuries like loss of epithelial brush border, dilation of tubules, tubular necrosis and cast production (black arrows), while renal injury area was markedly reduced in the AZA group (Fig. 1A and 1B). Then we detected the renal function by measuring serum creatinine and BUN, and the basal levels of serum creatinine and BUN were $3.87 \pm 0.38 \mathrm{mg} / \mathrm{L}$ and $37.32 \pm 1.98 \mathrm{mg} / 100 \mathrm{~mL}$, respectively. Furthermore, impaired renal function after I/R injury was improved by AZA treatment through bringing down the levels of both serum creatinine (from $17.14 \pm 1.96 \mathrm{mg} / \mathrm{L}$ to 9.47 $\pm 1.31 \mathrm{mg} / \mathrm{L}$ ) and BUN (from $72.28 \pm 14.57 \mathrm{mg} / 100 \mathrm{~mL}$ to $46.18 \pm 3.16 \mathrm{mg} / 100 \mathrm{~mL}$ ). Other basic parameters were shown in Table 1. 


\section{Cellular Physiology and Biochemistry}

Cell Physiol Biochem 2013;32:1151-1166

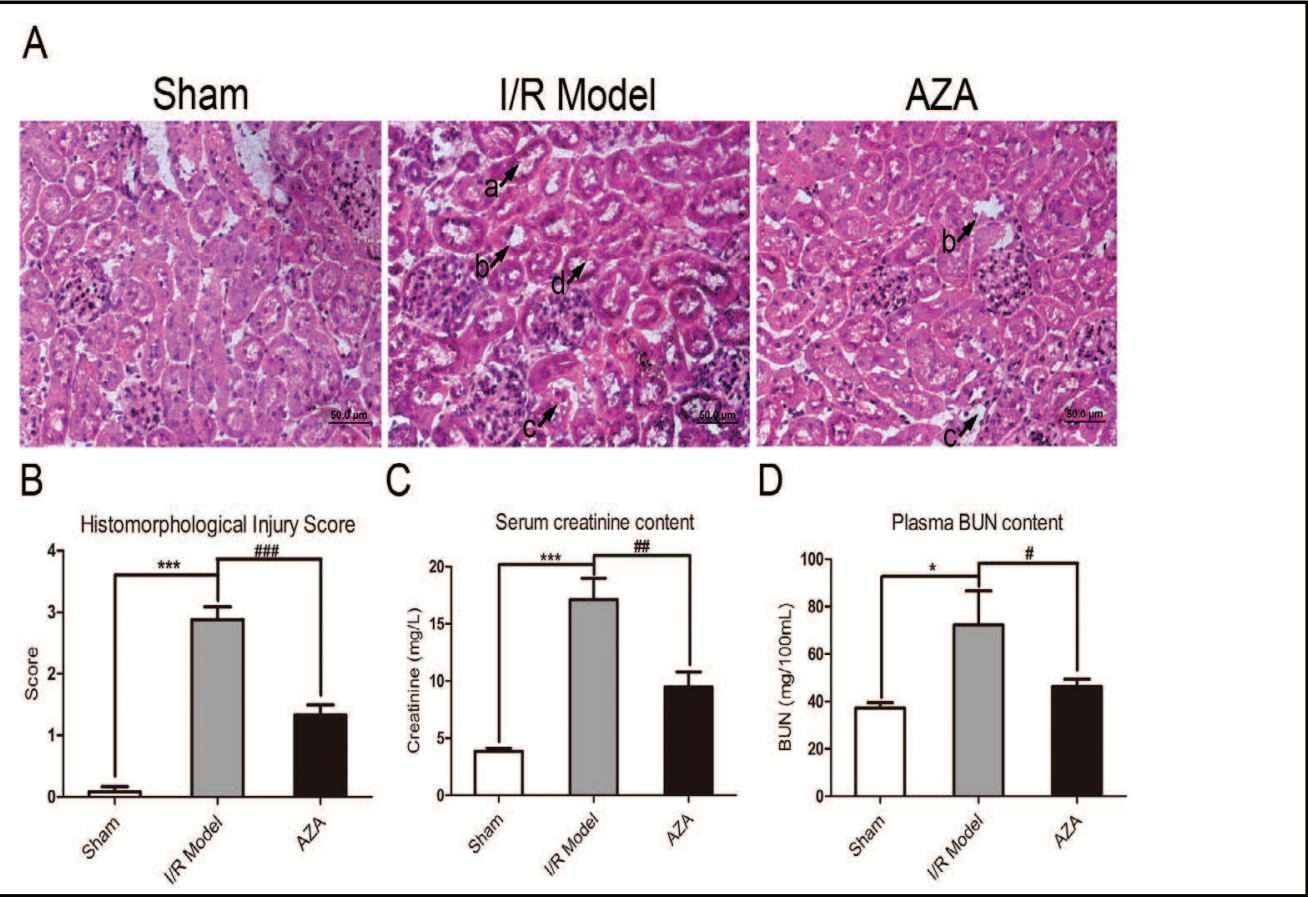

Fig. 1. AZA treatment improved mouse renal function after ischemia-reperfusion injury. (A) Representative light microscopy images of the renal cortex in mice subjected to sham operation (Sham, left panel), 30 min of left warm renal ischemia followed by $48 \mathrm{~h}$ of reperfusion with vehicle (I/R Model, middle panel) or acetazolamide treatment (AZA, right panel) (hematoxylin-eosin staining, original magnification $\times 400$ ). In the AZA group, $60 \mathrm{mg} / \mathrm{kg} /$ day of acetazolamide were administered (i.g.) for two consecutive days before ischemia insult and during $48 \mathrm{~h}$ of reperfusion. Black arrows indicated renal injuries including: a, loss of epithelial cell brush border; b, dilation of tubules; c, tubular necrosis; and d, cast formation. (B) Histogram of histomorphological injury scores of renal tissue damage indicated by hematoxylin-eosin staining. $\mathrm{N}=6$ per group. Serum creatinine levels (C) and blood urea nitrogen levels (D) in mice from three different groups, $\mathrm{n}=6$ mice per group. For all graphs: data were shown as mean \pm s.e.m. ${ }^{*} p<0.05,{ }^{* *} p<0.01,{ }^{* * *} p<0.001$ vs. sham group; \# $p<0.05$, \#\# $p<0.01$, \#\#\# $p<0.001$ vs. I/R group.

Table 1. Body weight, systemic blood pressure, serum and urine analysis of sham, I/R and AZA treated mice. $\mathrm{N}$ : number of mice in each group. [Na] and [K]: sodium and potassium concentration, respectively. FE $\mathrm{Na}$ and FE K: fractional excretion of sodium and potassium, respectively. Values are shown as mean \pm s.e.m. ${ }^{*} p<0.05$ vs. sham group. \# $p<0.05$ vs. I/R group.

\begin{tabular}{lccc}
\hline & Sham & I/R & AZA \\
\hline $\mathrm{N}$ & 7 & 8 & 8 \\
Body weight $(\mathrm{g})$ & $20.2 \pm 0.2$ & $20.7 \pm 0.5$ & $20.1 \pm 0.6$ \\
SBP, baseline $(\mathrm{mmHg})$ & $94 \pm 2.8$ & $94 \pm 3.1$ & $94 \pm 2.6$ \\
SBP, ischemia 30min $(\mathrm{mmHg})$ & $92 \pm 4.8$ & $84 \pm 6.1$ & $88 \pm 5.7$ \\
SBP, reperfusion 48h $(\mathrm{mmHg})$ & $94 \pm 1.4$ & $92 \pm 2.2$ & $92 \pm 3.6$ \\
Urine volume $(\mathrm{mL} / 24 \mathrm{~h})$ & $0.85 \pm 0.12$ & $0.34 \pm 0.14^{*}$ & $0.47 \pm 0.12$ \\
Urine creatinine $(\mathrm{mg} / \mathrm{L})$ & $1502 \pm 125.1$ & $934 \pm 51.4^{*}$ & $1209 \pm 156.8 \#$ \\
Creatinine excretion $(\mathrm{mg} / 24 \mathrm{~h})$ & $1.23 \pm 0.24$ & $0.28 \pm 0.14^{*}$ & $0.70 \pm 0.31 \#$ \\
Clearance of creatinine $(\mathrm{mL} / \mathrm{min})$ & $0.23 \pm 0.03$ & $0.03 \pm 0.01^{*}$ & $0.13 \pm 0.03^{\#}$ \\
Serum $[\mathrm{Na}](\mathrm{mmol} / \mathrm{L})$ & $135 \pm 0.7$ & $124 \pm 0.4^{*}$ & $132 \pm 0.5$ \# \\
Urine $[\mathrm{Na}](\mathrm{mmol} / \mathrm{L})$ & $161 \pm 3.4$ & $243 \pm 2.7^{*}$ & $182 \pm 4.4 \#$ \\
Na excretion $(\mu \mathrm{mol} / 24 \mathrm{~h})$ & $102 \pm 3.8$ & $124 \pm 4.3^{*}$ & $105 \pm 2.6 \#$ \\
FE Na $(\%)$ & $0.13 \pm 0.02$ & $2.63 \pm 0.49^{*}$ & $0.79 \pm 0.23$ \# \\
Serum $[\mathrm{K}](\mathrm{mmol} / \mathrm{L})$ & $4.9 \pm 0.12$ & $4.7 \pm 0.14$ & $4.7 \pm 0.05$ \\
Urine $[\mathrm{K}](\mathrm{mmol} / \mathrm{L})$ & $318.1 \pm 10.2$ & $339.9 \pm 14.0$ & $327.8 \pm 5.7$ \\
$\mathrm{~K}$ excretion $(\mu \mathrm{mol} / 24 \mathrm{~h})$ & $201.0 \pm 25.7$ & $267.9 \pm 38.1$ & $216.7 \pm 41.1$ \\
FE K $(\%)$ & $16.3 \pm 2.0$ & $42.5 \pm 9.0^{*}$ & $25.3 \pm 6.3 \#$ \\
\hline
\end{tabular}




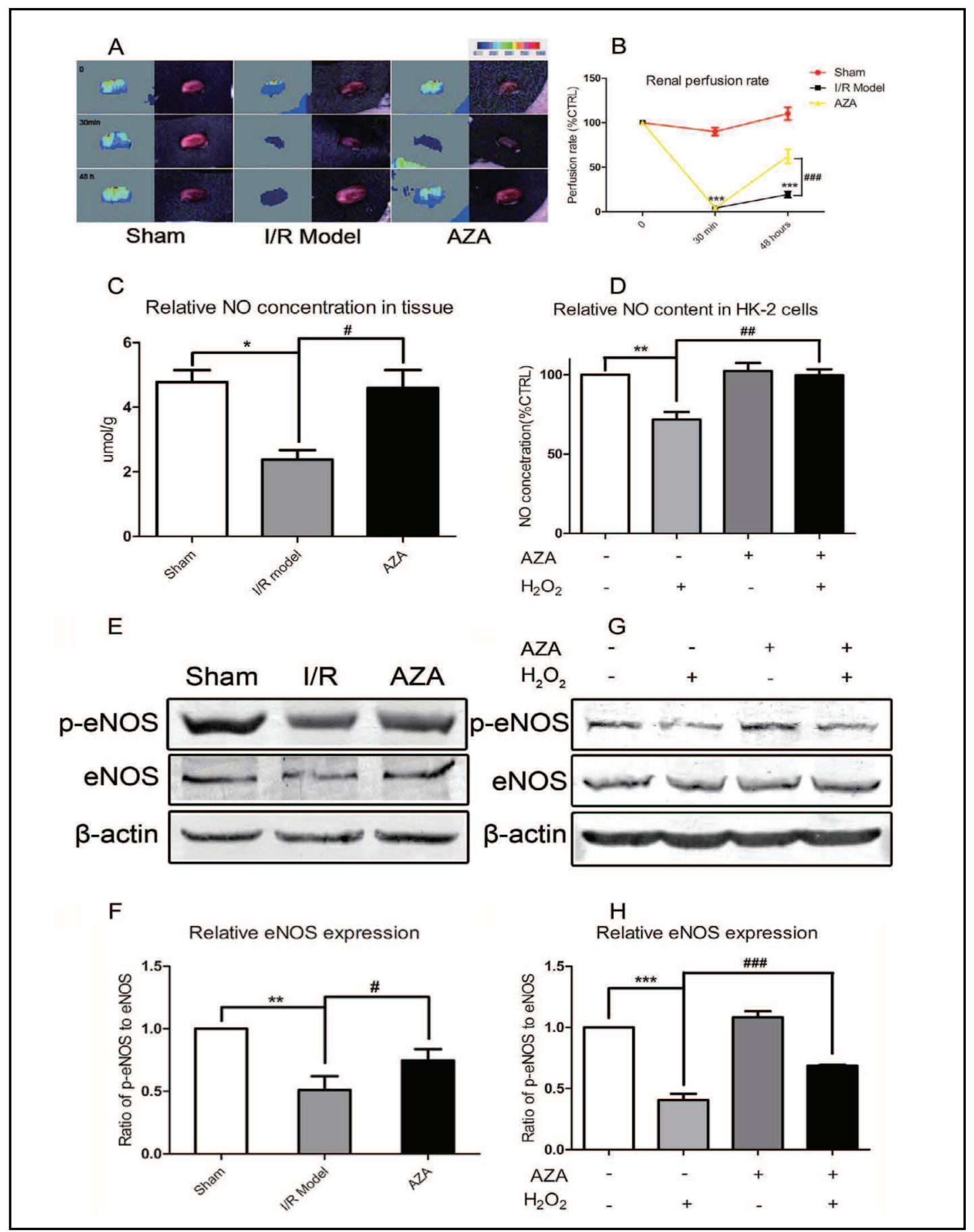

Fig. 2. AZA treatment restored impaired renal blood flow and increased nitric oxide (NO) concentrations by elevating the expression and activities of endothelial nitric oxide synthase (eNOS) after I/R injury both in vivo and in vitro. (A) Representative Laser Doppler images by scanning mouse kidneys in three different groups. For each group, images before ischemia insult (0), after $30 \mathrm{~min}$ of ischemia (30 min) and after $48 \mathrm{~h}$ of reperfusion (48h) were shown, respectively. For each group, both colourful laser Doppler images (left) indicating renal blood flow and phase-contrast images (right) indicating morphology of kidneys at each time point were shown respectively. A colourful scale illustrated variations in renal blood flow from minimal flow (dark blue) to high flow (red). (B) Statistics of renal perfusion rates from laser Doppler images at the beginning, after ischemia for $30 \mathrm{~min}$ and reperfusion for 48 hours. Red dots and lines: the sham group; black squares and lines: the I/R model group; yellow triangles and lines: the AZA treatment group. From 0 


\section{Cellular Physiology and Biochemistry}

Cell Physiol Biochem 2013;32:1151-1166

\begin{tabular}{l|l}
\hline DOI: $10.1159 / 000354515$ & (C) 2013 S. Karger AG, Basel
\end{tabular}

www.karger.com/cpb

An et al.: AZA Ameliorates Renal I/R Injury via HIF-1a

min to 30 min of ischemia, the yellow line of the AZA group coincided with the black line of the I/R group. $\mathrm{N}=$ 6 mice per group. (C) Relative NO levels ( $\mu \mathrm{mol} / \mathrm{g}$ ) in mouse kidneys in the sham, I/R Model and AZA groups, normalised to the protein concentrations of kidney extracts. $\mathrm{N}=6$ mice per group. Data were shown as mean \pm s.e.m. $* p<0.05$ vs. sham group; \# $p<0.05$ vs. I/R group. (D) Relative NO levels (\% CTRL) normalised to the levels of the control group (AZA- and $\mathrm{H}_{2} \mathrm{O}_{2}$ ) ) in $\mathrm{HK}-2$ cells pretreated by $3 \times 10^{-7} \mathrm{~mol} / \mathrm{L}$ AZA (AZA+) or vehicle (AZA-) for 24 hours followed by stimulation of $500 \mu \mathrm{mol} / \mathrm{L} \mathrm{H}_{2} \mathrm{O}_{2}\left(\mathrm{H}_{2} \mathrm{O}_{2}+\right)$ or a corresponding vehicle $\left(\mathrm{H}_{2} \mathrm{O}_{2}-\right)$ for eight hours, and culture supernatant was collected for $\mathrm{NO}$ measurement. $\mathrm{N}=3$ independent experiments per group. Data were shown as mean \pm s.e.m. ${ }^{* *} p<0.01$ vs. AZA- and $\mathrm{H}_{2} \mathrm{O}_{2}$ - group; \#\# $p<0.01$ vs. AZA- and $\mathrm{H}_{2} \mathrm{O}_{2}+$ group. (E) Representative immunoblotting images of phosphorylated eNOS (p-eNOS), eNOS and $\beta$-actin in mouse kidneys from the sham, I/R Model and AZA treatment groups from six independent western blotting experiments. (F) Densitometric quantification of relative band intensities normalised to $\beta$-actin from the immunoblotting images of p-eNOS, eNOS and $\beta$-actin in mouse kidneys from three groups. N = 6 independent Western Blot experiments per group. Data were shown as mean \pm s.e.m. ${ }^{* *} p<0.01$ vs. sham group; \# $p<0.05$ vs. I/R group. (G) Representative immunoblotting images of p-eNOS, eNOS and $\beta$-actin in HK-2 cells pretreated with AZA or vehicle for 24 hours followed by simulation of $\mathrm{H}_{2} \mathrm{O}_{2}$ or vehicle for eight hours from three independent western blotting experiments. $(\mathrm{H})$ Densitometric quantification of relative band intensities normalised to $\beta$-actin from immunoblotting images of p-eNOS, eNOS and $\beta$-actin in HK- 2 cells from four groups. $\mathrm{N}=3$ independent Western Blot experiments per group. Data were shown as mean \pm s.e.m. *** $p<0.001$ vs. AZA- and $\mathrm{H}_{2} \mathrm{O}_{2}$ - group; \#\#\# $p<0.001$ vs. AZA- and $\mathrm{H}_{2} \mathrm{O}_{2}+$ group.

\section{Effects of acetazolamide on $\mathrm{H}_{2} \mathrm{O}_{2}$ stimulated human kidney-2 (HK-2) cells}

To confirm the above in vivo findings, an in vitro $\mathrm{H}_{2} \mathrm{O}_{2}$ stimulated $\mathrm{HK}-2$ cell model was used to mimic I/R injury [19]. Based on the findings of optimizing conditions, stimulation with $500 \mu \mathrm{mol} / \mathrm{L} \mathrm{H}_{2} \mathrm{O}_{2}$ for eight hours was utilised in subsequent experiments. $\mathrm{H}_{2} \mathrm{O}_{2}$ injury caused remarkable reduction of cell viability $(42.8 \pm 3.8 \%$ of control), while pretreatment of $3 \times 10^{-7} \mathrm{~mol} / \mathrm{L}$ AZA for 24 hours substantially improved HK-2 cell viability to $69.2 \pm 4.5 \%$ of control.

\section{Effects of acetazolamide on renal blood flow and nitric oxide production}

AZA has been reported to exhibit a vasodilatation effect on the kidneys in the clinical setting $[15,18]$, however no report is found about the association between such effect and renal protection. In light of our observation of AZA's protective role against renal I/R injury, we hypothesised that AZA could affect renal blood flow due to its vasodilatation effect. Laser Doppler images (Fig. 2A and 2B) demonstrated that impaired renal blood flow after I/R injury was restored after AZA treatment, and the perfusion rate recovered from $19.1 \pm 4.1 \%$ $(\mathrm{I} / \mathrm{R})$ to $62.3 \pm 8.2 \%(\mathrm{AZA})$ normalised to levels in the sham group.

Next, the involvement of NO, a key vasodilator to increase renal blood flow was explored in AZA's vasodilatation effect [24]. The levels of NO were examined in both mouse kidneys and cultured cells, and marked increase of NO production by AZA was seen (Fig. 2C and 2D). With respect to the crucial role of nitric oxide synthase (NOS) in catalyzing NO production [23], it was possible that AZA elevated NO levels by regulating NOS expression and/or activity. We found that constitutive NOS (cNOS) and total NOS (tNOS) activities were significantly increased after AZA treatment. The levels of activated cNOS (mainly phosphorylated eNOS (p-eNOS)) were detected by immunoblotting. I/R injury resulted in the reduction of p-eNOS level which was then reversed by AZA in vivo (Fig. $2 \mathrm{E}$ and $2 \mathrm{~F}$ ) and in vitro (Fig. $2 \mathrm{G}$ and $2 \mathrm{H})$. These results suggested that AZA could increase NO levels through promoting eNOS activation, leading to its protective effect on renal blood flow.

\section{Effects of acetazolamide on cell apoptosis both in vivo and in vitro}

In addition to impaired renal blood perfusion, apoptosis also mediates acute kidney injury after I/R insult [9]. Meanwhile, in vitro studies indicated that AZA treatment could improve renal cell survival after injury. In the present study, we confirmed that AZA treatment 


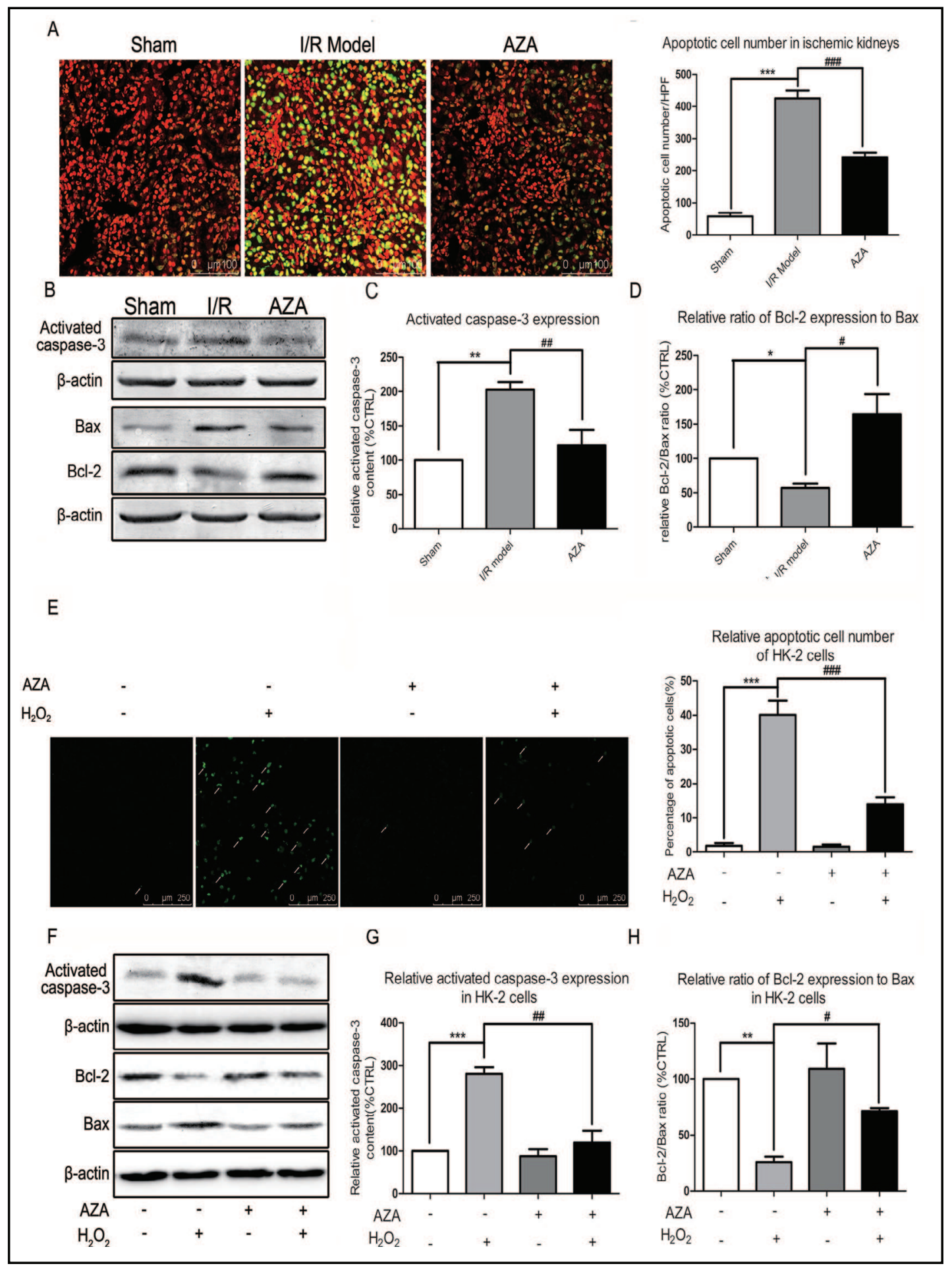

Fig. 3. AZA treatment exerted anti-apoptotic effect in mouse kidneys and HK-2 cells after renal I/R injury. (A) Quantification of the amounts of relative apoptotic cells illustrated by terminal deoxynucleotidyl transferase biotin-dUTP nick end labeling (TUNEL) staining (representative images see left panel) in mouse kidneys from the sham, I/R Model and AZA treatment groups. The number of TUNEL-positive cells per highpower field (HPF) was counted for statistics (right panel). $\mathrm{N}=6$ independent TUNEL experiments per group. Representative immunoblotting images (B) of activated caspase-3, Bax, Bcl-2 and $\beta$-actin in mouse kidneys in three groups from six independent western blotting experiments and densitometric quantification of relative band intensities of (C) activated caspase- 3 and (D) relative ratio of Bcl-2/Bax normalised to $\beta$-actin. 


\section{Cellular Physiology and Biochemistry}

Cell Physiol Biochem 2013;32:1151-1166 \begin{tabular}{l|l}
\hline DOI: $10.1159 / 000354515$ & (C) 2013 S. Karger AG, Basel
\end{tabular}

Publisned onine: November 11, $2013 \quad$ www.karger.com/cpb

An et al.: AZA Ameliorates Renal I/R Injury via HIF-1a

For all graphs: data were presented as mean \pm s.e.m. ${ }^{*} p<0.05,{ }^{* *} p<0.01,{ }^{* * *} p<0.001$ vs. sham group; \# $p<0.05$, \#\# $p<0.01$, \#\#\# $p<0.001$ vs. I/R group. (E) Quantification of the number of relative apoptotic cells illustrated by TUNEL staining (representative images see left panel) in HK-2 cells pretreated with AZA or vehicle for 24 hours followed by stimulation of $\mathrm{H}_{2} \mathrm{O}_{2}$ or vehicle for eight hours. The percentage of each group was calculated by comparing the number of TUNEL-positive cell to that of total cells per HPF (right panel). $\mathrm{N}=3$ independent TUNEL experiments per group. Representative immunoblotting images (F) of activated caspase-3, Bax, Bcl-2 and $\beta$-actin in HK-2 cells from four groups from three independent western blotting experiments and densitometric quantification of relative band intensities of $(\mathrm{G})$ activated caspase- 3 and $(\mathrm{H})$ relative ratio of $\mathrm{Bcl}-2 / \mathrm{Bax}$ normalised to $\beta$-actin. For all graphs: data were shown as mean \pm s.e.m. ${ }^{* *} p<0.01$, *** $p<0.001$ vs. AZA- and $\mathrm{H}_{2} \mathrm{O}_{2}$ - group; \# $p<0.05$, \#\# $p<0.01$ vs. AZA- and $\mathrm{H}_{2} \mathrm{O}_{2}+$ group.

could significantly decrease the number of apoptotic cells both in vivo (Fig. 3A) and in vitro (Fig. 3E).

Then, the levels of activated caspase-3, Bcl-2 and Bax, three key apoptosis related proteins [25] were measured by immunoblotting. AZA reduced the level of activated caspase- 3 after I/R injury but elevated the ratio of Bcl-2/Bax in comparison with the injury group (Fig. 3B3D). This finding was further supported by the data from HK-2 cells. As shown in Figures $3 \mathrm{~F}-3 \mathrm{H}, \mathrm{AZA}$ treatment prevented casapse-3 activation and increased Bcl-2/Bax ratio.

Role of hypoxia-inducible factor-1 $\alpha$ in the renoprotective effect of acetazolamide

HIF- $1 \alpha$ plays an important protective role against AKI [14,26, 27], which is related to its downstream proteins including the vascular endothelial growth factor (VEGF) [28], NOS [12, 29] and Bcl-2 [30, 31]. Based on our previous findings, we hypothesised that AZA performed its renoprotective function by modulating eNOS and Bcl-2 which could be connected with HIF- $1 \alpha$. To test this hypothesis, HIF- $1 \alpha$ protein levels were detected in vivo and in vitro. As shown in Figures 4A-4D, I/R injury or $\mathrm{H}_{2} \mathrm{O}_{2}$ stimulation substantially attenuated HIF-1 $\alpha$ expression which was then markedly increased after AZA treatment.

To further investigate that modulation of eNOS and Bcl-2 by AZA was dependent on HIF- $1 \alpha$ up-regulation, loss-of-function on HIF- $1 \alpha$ by RNA interference was conducted in our present study. The expression of HIF- $1 \alpha$ was knocked down by $50 \%$ in HK-2 cells by specific siRNA. Immunoblotting results demonstrated that knockdown of HIF-1 $\alpha$ neutralised AZA's ability to elevate eNOS phosphorylation or Bcl-2/Bax ratio (Fig. 4E-4H). Similarly, HIF-1 $\alpha$ siRNA knockdown blocked AZA mediated NO production and cell viability improvement (Fig. 4I-4J). As indicated in the TUNEL assay, AZA could significantly reduce apoptosis in the wild-type HK-2 cells, which was then cancelled in HIF-1 $\alpha$ siRNA knockdown cells (Fig. 4K and $4 \mathrm{~L})$.

Role of the PI3K/Akt signaling pathway in the regulating effects of acetazolamide upon hypoxia-inducible factor- $1 \alpha$

Both phosphoinositide 3-kinase (PI3K)/Akt and ERK are key signaling pathways regulating HIF-1 $\alpha$ expression $[32,33]$. PI3K/Akt is also an important survival pathway against AKI [34]. To investigate the role of the PI3K/Akt signaling pathway in the regulating effect of AZA on HIF- $1 \alpha$, the phosphorylation levels of PI3K, Akt, mTOR and endogenous PI3K inhibitor PTEN were examined in HK-2 cells treated with AZA for 0 to 4 hours. As a result, the PI3K/Akt/mTOR pathway was sequentially activated (PI3K p-p85 peaked at 5 min; p-Akt at $15 \mathrm{~min}$; and p-mTOR at 1 hour) which then returned to control levels. The decrease of PTEN expression was in a time-dependent manner (Fig. 5A). In addition, the up-regulation of HIF$1 \alpha$, eNOS and Bcl-2 by AZA was reversed after treatment with the PI3K/Akt specific inhibitor LY294002 (Fig. 5B). Inhibition of PI3K/Akt by LY294002 also blocked the NO production and the cellular protection of AZA in HK-2 cells (Fig. 5C and 5D). These results suggested the upregulation of HIF- $1 \alpha$ by AZA through activating the PI3K/Akt pathway. 


\section{Cellular Physiology $\quad$ Cell Physiol Biochem 2013;32:1151-1166 \begin{tabular}{l|l|l|}
\hline DOI: 10.1159/000354515 & O 2013 S. Karger AG, Basel \\
\hline
\end{tabular}

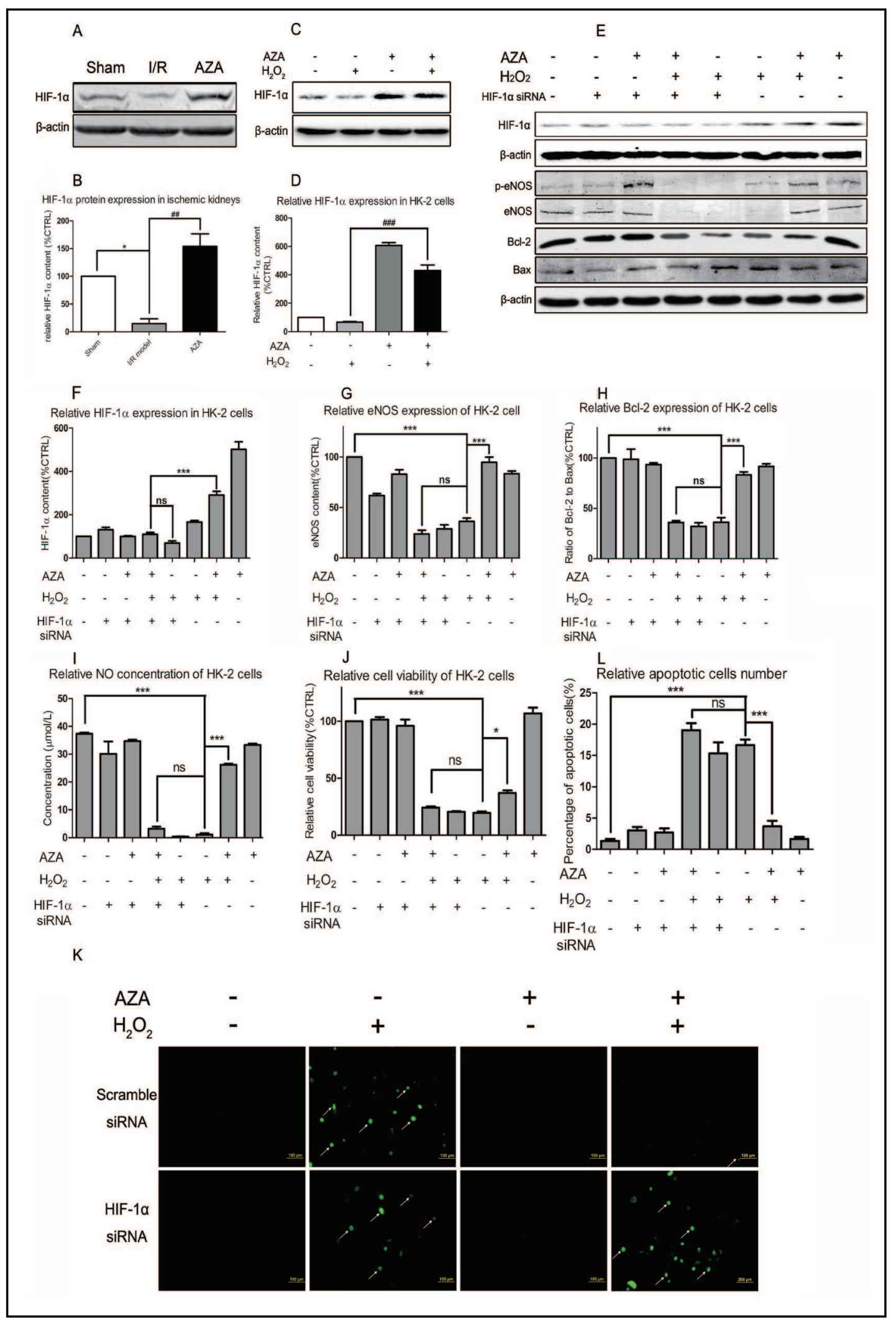

Fig. 4. AZA treatment increased hypoxia-inducible factor-1 $\alpha$ (HIF-1 $\alpha$ ) both in vivo and in vitro and HIF$1 \alpha$ siRNA knockdown reversed the effect of AZA. (A) Representative immunoblotting images of HIF-1 $\alpha$ and $\beta$-actin in mouse kidneys from the sham, I/R Model and AZA treatment groups from six independent 


\section{Cellular Physiology and Biochemistry}

Cell Physiol Biochem 2013;32:1151-1166

\begin{tabular}{l|l}
\hline DOI: $10.1159 / 000354515$ & (c) 2013 S. Karger AG, Basel
\end{tabular}

www.karger.com/cpb

An et al.: AZA Ameliorates Renal I/R Injury via HIF-1a

western blotting experiments. (B) Densitometric quantification of relative band intensities normalised to $\beta$-actin from the immunoblotting images of HIF- $1 \alpha$ and $\beta$-actin in mouse kidneys from three groups. $\mathrm{N}=6$ independent Western Blot experiments per group. Data were shown as mean \pm s.e.m. ${ }^{*} p<0.05$ vs. sham group; \#\# $p<0.01$ vs. I/R group. (C) Representative immunoblotting images of HIF- $1 \alpha$ and $\beta$-actin in HK-2 cells pretreated with AZA or vehicle for 24 hours followed by stimulation of $\mathrm{H}_{2} \mathrm{O}_{2}$ or vehicle for eight hours from three independent western blotting experiments. (D) Densitometric quantification of relative band intensities normalised to $\beta$-actin from the immunoblotting images of HIF- $1 \alpha$ and $\beta$-actin in HK- 2 cells from four groups. $\mathrm{N}=3$ independent Western Blot experiments per group. Data were shown as mean \pm s.e.m. ${ }^{* *}$ $p<0.01$ vs. AZA- and $\mathrm{H}_{2} \mathrm{O}_{2}$ - group; \#\# $p<0.01$ vs. AZA- and $\mathrm{H}_{2} \mathrm{O}_{2}+$ group. (E) Representative immunoblotting images of HIF- $1 \alpha$, p-eNOS, eNOS, Bcl-2, Bax and $\beta$-actin in HK-2 cells incubated with HIF- $1 \alpha$ siRNA or scramble siRNA for 72 hours, while being pretreated with AZA or vehicle for 24 hours followed by stimulation of $\mathrm{H}_{2} \mathrm{O}_{2}$ for eight hours from three independent western blotting experiments. Densitometric quantification of relative (F) HIF- $1 \alpha,(\mathrm{G})$ eNOS and $(\mathrm{H}) \mathrm{Bcl}-2$ band intensities normalised to $\beta$-actin from the immunoblotting images in HK-2 cells from eight groups. $\mathrm{N}=3$ independent Western Blot experiments per group. For all graphs: data were shown as mean \pm s.e.m. In Figure $4 \mathrm{~F}$, ${ }^{* * *} p<0.001$ vs. AZA-, $\mathrm{H}_{2} \mathrm{O}_{2}$ - and HIF- $1 \alpha$ siRNA-group. In Figures 4G and 4H, ${ }^{* * *} p<0.001$; ns meant no significance. (I) Relative NO concentrations measured in HK-2 cells incubated with HIF-1 $\alpha$ siRNA (HIF-1 $\alpha$ siRNA +) or scramble siRNA (negative control, HIF-1 $\alpha$ siRNA -) for 72 hours, while being pretreated with AZA or vehicle for 24 hours followed by stimulation of $\mathrm{H}_{2} \mathrm{O}_{2}$ for eight hours (eight groups in total); culture supernatant was collected for NO measurement. $\mathrm{N}=3$ independent experiments per group. (J) Cell viability (\% CTRL) normalised to the levels of the control group (AZA-, H2O2- and HIF-1 $\alpha$ siRNA- group) measured from HK-2 cells in eight groups mentioned as Figure 4E. $\mathrm{N}=3$ independent experiments per group. (K) Representative fluorescence photomicrographs of HK-2 cells illustrating apoptotic cells by TUNEL staining from three independent experiments, with green dots indicating TUNEL-positive cells, original magnification $\times 200$. (L) Statistical histograms of relative apoptotic cells per high-powered field (HPF) from TUNEL staining images of HK-2 cell in eight groups, and the percentage of each group was calculated by comparing the number of TUNEL-positive cell to that of total cells per HPF. $\mathrm{N}=3$ independent TUNEL experiments per group. For Figures 4I, 4J and 4L, data were presented as mean \pm s.e.m. ${ }^{*} p<0.05 ;{ }^{* * *} p<0.001$; ns meant no significance.

\section{Discussion}

Ischemia/reperfusion, the leading cause of AKI, commonly occurs in various medical conditions and surgical procedures such as kidney transplantation [35]. Regulation of AKI after I/R injury holds the potential to prevent from early graft dysfunction [7]. In the present study, the renoprotective role of AZA and its underlying mechanism were investigated. Herein, we confirmed for the first time that AZA could effectively protect against I/R induced AKI, which improved renal histomorphology and function after I/R injury while preventing HK-2 cells from $\mathrm{H}_{2} \mathrm{O}_{2}$ induced cell injury. Similarly, there have been reports about the reduced risks of contrast induced AKI by AZA [16, 17, 36].

As a carbonic anhydrase inhibitor and a diuretic agent, AZA was initially regarded to attenuate I/R induced AKI through an increase in urine output. However, surprisingly compared with the sham group no significant further increase in mouse urine volumes was seen in our experiments (Table 1). Thus, such renoprotective effect may be attributed to novel mechanisms other than carbonic anhydrase inhibition. Generally, HIF-1 $\alpha$ has been documented as a beneficial transcriptional factor mediating cells adaptation against I/R induced injury [26, 27, 37]. Hill et al. [38] reported that hif $1 \alpha^{+/-}$mice exhibited more severe histologic injury and more impaired renal function after kidney I/R insult. Another report proved that induction of HIF- $1 \alpha$ by silencing its degradation enzyme Prolyl Hydroxylase Domain-1 (PHD-1 $\%$ ) attenuated myocardial I/R injury through up-regulating its target genes including eNOS and Bcl-2 [12]. Repetitive hypoxic preconditioning could ameliorate renal I/R injury through HIF-1 $\alpha$-dependent Bcl-2 anti-apoptotic pathway [39]. On the contrary, a few studies suggested that HIF- $1 \alpha$ did not participate in the protective effect under I/R injury $[40,41]$. Although there are conflicts about the protective role of HIF- $1 \alpha$ against I/R 
Fig. 5. AZA treatment activated the PI3K/Akt/mTOR signaling pathway and the protective effect of AZA treatment upon HK-2 cells were eliminated by the PI3K/Akt inhibitor LY294002. (A) Representative immunoblotting images of phosphorylated phosphoinositide 3-kinase p85 (PI3K, p-p85), PI3K p85, phosphorylated Akt (p-Akt), Akt, phosphorylated mammalian target of rapamycin (pmTOR), mTOR, phosphatase and tensin homolog (PTEN) and $\beta$-actin in HK- 2 cells treated with $3 \times 10^{-7} \mathrm{~mol} / \mathrm{L}$ AZA from 0 to 4 hours (8 time points in total) from three independent western blotting experiments. (B) Representative immunoblotting images of HIF-1 $\alpha$, p-eNOS, eNOS, Bcl-2, Bax and $\beta$-actin in HK-2 cells pre-incubated with the PI3K/Akt inhibitor LY294002 (20 $\mu \mathrm{mol} / \mathrm{L}, \mathrm{LY} 294002+)$ or vehicle (LY294002 -) for 1 hour followed by treatment with AZA or vehicle for 24 hours followed by stimulation of $\mathrm{H}_{2} \mathrm{O}_{2}$ for eight hours (eight groups in total) from three independent western blotting experiments. (C) Relative NO concentrations measured in HK-2 cells pre-incubated with LY294002 or vehicle for 1 hour, and then treated with AZA or vehicle for 24 hours

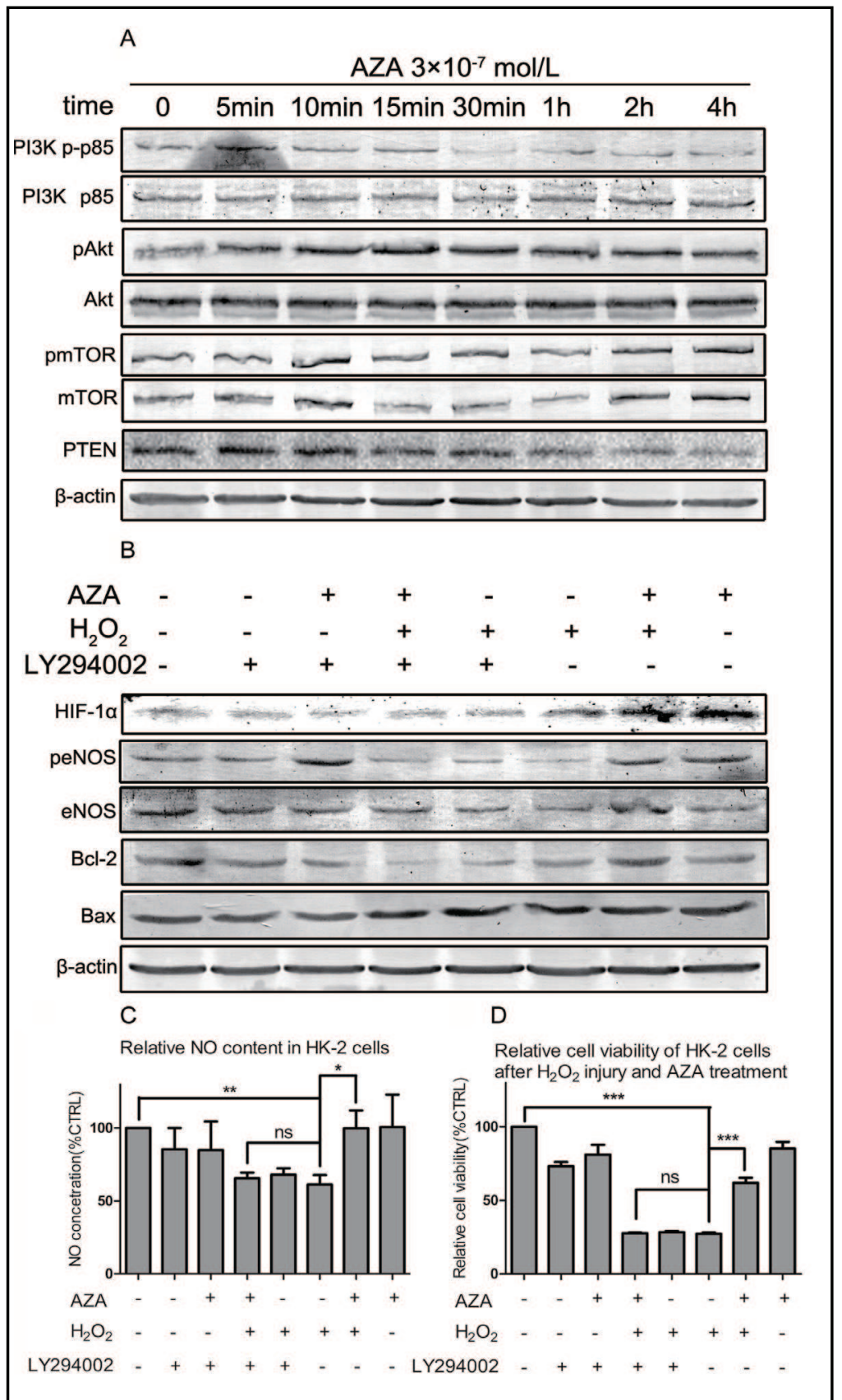

followed by stimulation of $\mathrm{H}_{2} \mathrm{O}_{2}$ for eight hours; culture supernatant was collected for $\mathrm{NO}$ measurement. $\mathrm{N}=3$ independent experiments per group. (D) Cell viability (\%CTRL) normalised to the level of the control group (AZA-, H2O2- and LY294002- group) measured in HK-2 cells in eight groups mentioned as Figure 5B. $\mathrm{N}=3$ independent experiments per group. For all graphs: data were shown as mean \pm s.e.m. ${ }^{*} p<0.05$; ${ }^{* *} p<0.01 ;{ }^{* * *} p<0.001$; ns meant no significance.

injury due to large amount of genes regulated by HIF-1, pharmacologically activating HIF-1 $\alpha$ is still considered an effective way to ameliorate I/R induced AKI. In our present study, HIF$1 \alpha$ activation has been linked to mediate the renoprotective role of AZA. We also showed that AZA increased eNOS-NO production and Bcl-2/Bax ratio in a HIF-1 $\alpha$-dependent manner, as HIF-1 $\alpha$ siRNA blocked the up-regulation of both eNOS and Bcl-2 and the subsequent protective effect. However, one limitation in our present study is that we only provided 


\section{Cellular Physiology and Biochemistry}

Cell Physiol Biochem 2013;32:1151-1166

\begin{tabular}{l|l}
\hline DOI: $10.1159 / 000354515$ & (c) 2013 S. Karger AG, Basel
\end{tabular}

Publisned onilne: N vovember 11, 2013 www.karger.com/cpb

An et al.: AZA Ameliorates Renal I/R Injury via HIF-1 $\alpha$

in vitro HIF- $1 \alpha$ siRNA evidence to elucidate HIF- $1 \alpha$ mediated the regulation of both eNOS and Bcl-2 by AZA, but in vivo experiments were still lacking. Thus, in future work, either specific inhibitor targeting HIF-1 $\alpha$ or hif $1 \alpha$ knock-out mice will be needed to further confirm our current findings.

AZA has been reported to dilate both small- and medium- caliber vessels in kidneys and other organs $[15,18,42,43]$, suggesting a possible role of AZA in increasing renal perfusion rates after I/R insult by vessel dilation. Consistently, AZA was found to restore impaired renal blood flow after I/R injury in our present study, possibly due to enhanced NO production. It was reported that AZA stimulated the production of the vasodilator nitric oxide (NO), resulting in an increase in blood flow because a NO synthase (NOS) inhibitor could reverse the effect of AZA on blood flow [44]. However, it is still controversial whether NO is the essential mediator of AZA induced vessels dilation, as one report said AZA could increase cerebral and ocular blood flow without any association with NO [45]. Given the conflicts, to verify the critical role of NO, in our future work specific eNOS inhibitor should be utilized.

How AZA restored HIF-1 $\alpha$ in the normoxic cell culture system is an important but not fully understood problem in our present study. There are mainly two ways in which HIF-1 $\alpha$ levels are regulated: transcriptional regulation and post-translational modulation (mostly degradation) $[10,26]$. From our results, activation of PI3K/Akt signaling pathway by AZA can be responsible for the transcriptional up-regulation of HIF- $1 \alpha$. However, the mechanism how AZA prevented HIF- $1 \alpha$ from oxygen-mediated degradation is still unclear. We speculated that: The first possible reason is acidosis induced by AZA treatment. It was reported that $\mathrm{pH}$ change during acidosis could trigger nucleolar sequestration of von Hippel-Lindau, thereby inhibiting its function to recognize hydroxylated HIF-1 $\alpha$ resulting in degradation $[46,47]$. It is well known that AZA treatment induces metabolic acidosis via carbonic anhydrase inhibition [48], and thus, we propose that AZA stabilizes HIF- $1 \alpha$ through acidosis mediated von Hippel-Lindau protein nucleolar sequestration and subsequent dysfunction. Consistent with our hypothesis, Xu et al. [49] reported that AZA significantly induced cerebral HIF-1 $\alpha$ under normoxic condition, and acidosis played an important role. Secondly, we cannot rule out the possibility that AZA increases HIF-1 $\alpha$ expression through, at least in part, modulating PHDs, which hydroxylate HIF-1 $\alpha$ leading to its degradation [50, 51]. Pharmacologically suppressing or genetically disruption of PHDs has also been proposed as effective strategies to stabilize and activate HIF-1 $\alpha[12,14]$. Accordingly, PHD inhibitors significantly reduced serum creatinine levels and renal injury scores after I/R injury by activation of HIF-1 $\alpha$ [52]. However, till now there is no report to demonstrate the relationship between AZA and PHDs. Therefore, to fully elucidate the mechanism how AZA prevents HIF- $1 \alpha$ from degradation under normoxic condition, the role of acidosis and impact of AZA on PHDs need to be further investigated in our future work.

We should always be aware that although AZA is an ancient diuretic agent affording potential clinical benefits [17], it should be used cautiously in patients with advancedstage renal failure because complications of AZA such as calcium phosphate kidney stones frequently occur [53]. A recent work by Betten et al. [54] supported our findings and showed that AZA administration effectively improved renal function on a patient with acute renal failure and alkalemia, possibly due to normalization of body $\mathrm{pH}$. Thus, the relationship between AZA and acute kidney injury is still disputed, and various patient conditions, AZA dosages and administration periods will result in different outcomes. Although our present study showed that AZA effectively ameliorated mouse renal ischemia-reperfusion injury, question is still remaining whether longer time or higher dose of AZA administration may cause further kidney injury. In summary, given both the beneficial effects and the complications of AZA treatment, our suggestion is that AZA can be used to ameliorate contrast or ischemia induced AKI within a short period, however, longer-time usage of this agent should be cautious. In addition, in our future work, a protective role of post-transplant AZA administration against I/R induced AKI still needs to be studied, and by utilizing the animal kidney transplantation model, whether the donor or the recipient should be treated with AZA also needs to be elucidated. 


\section{Cellular Physiology and Biochemistry}

Cell Physiol Biochem 2013;32:1151-1166 \begin{tabular}{l|l}
\hline DOI: $10.1159 / 000354515$ & (C) 2013 S. Karger AG, Basel
\end{tabular}

\begin{tabular}{l|l} 
Publisned online: November 11, 2013 & www.karger.com/cpb
\end{tabular}

An et al.: AZA Ameliorates Renal I/R Injury via HIF-1 $\alpha$

\section{Conclusion}

In conclusion, our present work provided multiple lines of evidence to support that AZA protected against renal I/R injury in mice and human HK-2 cells. AZA exerted renoprotective function via up-regulating HIF- $1 \alpha$ through activation of the PI3K/Akt signaling pathway. The increase of HIF-1 $\alpha$ enhanced the downstream eNOS/NO production and Bcl-2/Bax ratio, resulting in the improvement of renal blood flow and attenuation of cell apoptosis. Finally, AZA treatment restored mouse renal function against I/R induced AKI.

\section{Abbreviations}

AKI (acute kidney injury); ARF (acute renal failure); AZA (acetazolamide); Bcl-2 (B-cell lymphoma 2); BUN (blood urea nitrogen); ERK (extracellular regulated protein kinase); HIF- $1 \alpha$ (hypoxia-inducible factor-1 $\alpha$ ); HK-2 (human kidney-2); ICU (intensive care unit); I/R (ischemia-reperfusion); MAPK (mitogen activated protein kinase); NO (nitric oxide); NOS (nitric oxide synthase); eNOS (endothelial nitric oxide synthase); nNOS (neural nitric oxide synthase); PHD (prolyl hydroxylase domain); PI3K (phosphoinositide 3-kinase); PTEN (phosphatase and tensin homolog); mTOR (mammalian target of rapamycin); TUNEL (terminal deoxynucleotidyl transferase biotin-dUTP nick end labeling); VEGF (vascular endothelial growth factor); pVHL (von Hippel-Lindau).

\section{Conflict of Interest}

The authors declare no conflict of interests.

\section{Acknowledgements}

This work was supported by the National Natural Science Foundation of China (No. 91129727, 81020108031, 30973558, 81270049, and 81373405) and Research Fund from Ministry of Education of China (111 Projects No.B07001). The funders had no role in study design, data collection and analysis, decision to publish, or preparation of the manuscript.

\section{References}

1 Bellomo R, Kellum JA, Ronco C: Acute kidney injury. Lancet 2012;380:756-766.

2 Hsu CY, McCulloch CE, Fan D, Ordonez JD, Chertow GM, Go AS: Community-based incidence of acute renal failure. Kidney Int 2007;72:208-212.

3 Waikar SS, Liu KD, Chertow GM: Diagnosis, epidemiology and outcomes of acute kidney injury. Clin J Am Soc Nephrol 2008;3:844-861.

-4 Bagshaw SM, George C, Bellomo R: Early acute kidney injury and sepsis: A multicentre evaluation. Crit Care 2008;12:R47.

5 Mehta RL, Pascual MT, Soroko S, Savage BR, Himmelfarb J, Ikizler TA, Paganini EP, Chertow GM: Spectrum of acute renal failure in the intensive care unit: The picard experience. Kidney Int 2004;66:1613-1621.

6 Munshi R, Hsu C, Himmelfarb J: Advances in understanding ischemic acute kidney injury. BMC Med 2011;9:11.

7 Snoeijs MG, van Heurn LW, Buurman WA: Biological modulation of renal ischemia-reperfusion injury. Curr Opin Organ Transplant 2010;15:190-199.

8 Yarlagadda SG, Coca SG, Formica RN Jr, Poggio ED, Parikh CR: Association between delayed graft function and allograft and patient survival: A systematic review and meta-analysis. Nephrol Dial Transplant 2009;24:1039-1047. 


\section{Cellular Physiology and Biochemistry}

Cell Physiol Biochem 2013;32:1151-1166

An et al.: AZA Ameliorates Renal I/R Injury via HIF-1 $\alpha$

-9 Bonventre JV, Yang L: Cellular pathophysiology of ischemic acute kidney injury. J Clin Invest 2011;121:4210-4221.

10 Semenza GL: Oxygen sensing, homeostasis, and disease. N Engl J Med 2011;365:537-547.

11 Baranova O, Miranda LF, Pichiule P, Dragatsis I, Johnson RS, Chavez JC: Neuron-specific inactivation of the hypoxia inducible factor 1 alpha increases brain injury in a mouse model of transient focal cerebral ischemia. J Neurosci 2007;27:6320-6332.

12 Adluri RS, Thirunavukkarasu M, Dunna NR, Zhan L, Oriowo B, Takeda K, Sanchez JA, Otani H, Maulik G, Fong $\mathrm{GH}$, Maulik N: Disruption of hypoxia-inducible transcription factor-prolyl hydroxylase domain-1 (phd-1-/-) attenuates ex vivo myocardial ischemia/reperfusion injury through hypoxia-inducible factor1alpha transcription factor and its target genes in mice. Antioxid Redox Signal 2011;15:1789-1797.

13 Guo JY, Yang T, Sun XG, Zhou NY, Li FS, Long D, Lin T, Li PY, Feng L: Ischemic postconditioning attenuates liver warm ischemia-reperfusion injury through akt-enos-no-hif pathway. J Biomed Sci 2011;18:79.

-14 Weidemann A, Bernhardt WM, Klanke B, Daniel C, Buchholz B, Campean V, Amann K, Warnecke C, Wiesener MS, Eckardt KU, Willam C: Hif activation protects from acute kidney injury. J Am Soc Nephrol 2008;19:486494.

15 Horita Y, Yakabe K, Tadokoro M, Suyama N, Hayashida K, Kawano Y, Miyazaki M, Kohno S, Taura K: Renal circulatory effects of acetazolamide in patients with essential hypertension. Am J Hypertens 2006;19:282285.

-16 Assadi F: Acetazolamide for prevention of contrast-induced nephropathy: A new use for an old drug. Pediatr Cardiol 2006;27:238-242.

17 Kassamali R, Sica DA: Acetazolamide: A forgotten diuretic agent. Cardiol Rev 2011;19:276-278.

18 Taki K, Oogushi K, Hirahara K, Gai X, Nagashima F, Tozuka K: Preferential acetazolamide-induced vasodilation based on vessel size and organ: Confirmation of peripheral vasodilation with use of colored microspheres. Angiology 2001;52:483-488.

19 Park SW, Kim M, D'Agati VD, Lee HT: Sphingosine kinase 1 protects against renal ischemia-reperfusion injury in mice by sphingosine-1-phosphate1 receptor activation. Kidney Int 2011;80:1315-1327.

-20 Silva RC, Landgraf MA, Correa-Costa M, Semedo P, Cenedeze MA, Pacheco-Silva A, Landgraf RG, Camara NO: Acute kidney injury reduces phagocytic and microbicidal capacities of alveolar macrophages. Cell Physiol Biochem 2013;31:179-188.

21 Brooks C, Wei Q, Cho SG, Dong Z: Regulation of mitochondrial dynamics in acute kidney injury in cell culture and rodent models. J Clin Invest 2009;119:1275-1285.

22 Wei Q, Bhatt K, He HZ, Mi QS, Haase VH, Dong Z: Targeted deletion of dicer from proximal tubules protects against renal ischemia-reperfusion injury. J Am Soc Nephrol 2010;21:756-761.

-23 Tie L, Yang HQ An Y, Liu SQ Han J, Xu Y, Hu M, Li WD, Chen AF, Lin ZB, Li XJ: Ganoderma lucidum polysaccharide accelerates refractory wound healing by inhibition of mitochondrial oxidative stress in type 1 diabetes. Cell Physiol Biochem 2012;29:583-594.

-24 Satake A, Takaoka M, Nishikawa M, Yuba M, Shibata Y, Okumura K, Kitano K, Tsutsui H, Fujii K, Kobuchi S, Ohkita M, Matsumura Y: Protective effect of 17beta-estradiol on ischemic acute renal failure through the pi3k/akt/enos pathway. Kidney Int 2008;73:308-317.

25 Havasi A, Borkan SC: Apoptosis and acute kidney injury. Kidney Int 2011;80:29-40.

26 Haase VH: The vhl/hif oxygen-sensing pathway and its relevance to kidney disease. Kidney Int 2006;69:1302-1307.

27 Gunaratnam L, Bonventre JV: Hif in kidney disease and development. J Am Soc Nephrol 2009;20:18771887.

28 Ke Q Costa M: Hypoxia-inducible factor-1 (hif-1). Mol Pharmacol 2006;70:1469-1480.

29 Coulet F, Nadaud S, Agrapart M, Soubrier F: Identification of hypoxia-response element in the human endothelial nitric-oxide synthase gene promoter. J Biol Chem 2003;278:46230-46240.

-30 Oh SW, Ahn JM, Lee YM, Kim S, Chin HJ, Chae DW, Na KY: Activation of hypoxia-inducible factor by cobalt is associated with the attenuation of tissue injury and apoptosis in cyclosporine-induced nephropathy. Tohoku J Exp Med 2012;226:197-206.

-31 Yu HJ, Chien CT, Lai YJ, Lai MK, Chen CF, Levin RM, Hsu SM: Hypoxia preconditioning attenuates bladder overdistension-induced oxidative injury by up-regulation of bcl-2 in the rat. J Physiol 2004;554:815-828.

-32 Lim JH, Lee ES, You HJ, Lee JW, Park JW, Chun YS: Ras-dependent induction of hif-1alpha785 via the raf/ mek/erk pathway: A novel mechanism of ras-mediated tumor promotion. Oncogene 2004;23:9427-9431. 


\section{Cellular Physiology and Biochemistry}

Cell Physiol Biochem 2013;32:1151-1166

\begin{tabular}{l|l}
\hline DOI: $10.1159 / 000354515$ & (c) 2013 S. Karger AG, Basel
\end{tabular}

An et al.: AZA Ameliorates Renal I/R Injury via HIF-1 $\alpha$

-33 Li J, Davidson G, Huang Y, Jiang BH, Shi X, Costa M, Huang C: Nickel compounds act through phosphatidylinositol-3-kinase/akt-dependent, p70(s6k)-independent pathway to induce hypoxia inducible factor transactivation and cap43 expression in mouse epidermal cl41 cells. Cancer Res 2004;64:94-101.

34 Chen J, Chen JK, Harris RC: Deletion of the epidermal growth factor receptor in renal proximal tubule epithelial cells delays recovery from acute kidney injury. Kidney Int 2012;82:45-52.

-35 Martin RK: Acute kidney injury: Advances in definition, pathophysiology, and diagnosis. AACN Adv Crit Care 2010;21:350-356.

-36 Pakfetrat M, Nikoo MH, Malekmakan L, Tabandeh M, Roozbeh J, Nasab MH, Ostovan MA, Salari S, Kafi M, Vaziri NM, Adl F, Hosseini M, Khajehdehi P: A comparison of sodium bicarbonate infusion versus normal saline infusion and its combination with oral acetazolamide for prevention of contrast-induced nephropathy: A randomized, double-blind trial. Int Urol Nephrol 2009;41:629-634.

-37 Rosenberger C, Rosen S, Shina A, Bernhardt W, Wiesener MS, Frei U, Eckardt KU, Heyman SN: Hypoxiainducible factors and tubular cell survival in isolated perfused kidneys. Kidney Int 2006;70:60-70.

-38 Hill P, Shukla D, Tran MG, Aragones J, Cook HT, Carmeliet P, Maxwell PH: Inhibition of hypoxia inducible factor hydroxylases protects against renal ischemia-reperfusion injury. J Am Soc Nephrol 2008;19:39-46.

39 Yang CC, Lin LC, Wu MS, Chien CT, Lai MK: Repetitive hypoxic preconditioning attenuates renal ischemia/reperfusion induced oxidative injury via upregulating hif- 1 alpha-dependent bcl- 2 signaling. Transplantation 2009;88:1251-1260.

-40 Knudsen AR, Kannerup AS, Gronbaek H, Andersen KJ, Funch-Jensen P, Frystyk J, Flyvbjerg A, Mortensen FV: Effects of ischemic pre- and postconditioning on hif-1alpha, vegf and tgf-beta expression after warm ischemia and reperfusion in the rat liver. Comp Hepatol 2011;10:3.

-41 Cursio R, Miele C, Filippa N, Van Obberghen E, Gugenheim J: Liver hif-1 alpha induction precedes apoptosis following normothermic ischemia-reperfusion in rats. Transplant Proc 2008;40:2042-2045.

-42 Teppema LJ, Bijl H, Romberg RR, Dahan A: Antioxidants reverse depression of the hypoxic ventilatory response by acetazolamide in man. J Physiol 2006;572:849-856.

43 Iida H, Nakagawara J, Hayashida K, Fukushima K, Watabe H, Koshino K, Zeniya T, Eberl S: Multicenter evaluation of a standardized protocol for rest and acetazolamide cerebral blood flow assessment using a quantitative spect reconstruction program and split-dose 123i-iodoamphetamine. J Nucl Med 2010;51:1624-1631.

-44 Tuettenberg J, Heimann A, Kempski 0: Nitric oxide modulates cerebral blood flow stimulation by acetazolamide in the rat cortex: A laser doppler scanning study. Neurosci Lett 2001;315:65-68.

45 Kiss B, Dallinger S, Findl O, Rainer G, Eichler HG, Schmetterer L: Acetazolamide-induced cerebral and ocular vasodilation in humans is independent of nitric oxide. Am J Physiol 1999;276:R1661-1667.

46 Mekhail K, Gunaratnam L, Bonicalzi ME, Lee S: Hif activation by ph-dependent nucleolar sequestration of vhl. Nat Cell Biol 2004;6:642-647.

47 Willam C, Warnecke C, Schefold JC, Kugler J, Koehne P, Frei U, Wiesener M, Eckardt KU: Inconsistent effects of acidosis on hif-alpha protein and its target genes. Pflugers Arch 2006;451:534-543.

48 Sporn A, Scothorn DM, Terry JE: Metabolic acidosis induced by acetazolamide. J Am Optom Assoc 1991;62:934-937.

49 Xu J, Peng Z, Li R, Dou T, Xu W, Gu G, Liu Y, Kang Z, Tao H, Zhang JH, Ostrowski RP, Lu J, Sun X: Normoxic induction of cerebral hif-1alpha by acetazolamide in rats: Role of acidosis. Neurosci Lett 2009;451:274278.

50 Flagg SC, Martin CB, Taabazuing CY, Holmes BE, Knapp MJ: Screening chelating inhibitors of hif-prolyl hydroxylase domain 2 (phd2) and factor inhibiting hif (fih). J Inorg Biochem 2012;113:25-30.

-51 Harten SK, Ashcroft M, Maxwell PH: Prolyl hydroxylase domain inhibitors: A route to hif activation and neuroprotection. Antioxid Redox Signal 2010;12:459-480.

-52 Bernhardt WM, Gottmann U, Doyon F, Buchholz B, Campean V, Schodel J, Reisenbuechler A, Klaus S, Arend M, Flippin L, Willam C, Wiesener MS, Yard B, Warnecke C, Eckardt KU: Donor treatment with a phd-inhibitor activating hifs prevents graft injury and prolongs survival in an allogenic kidney transplant model. Proc Natl Acad Sci U S A 2009;106:21276-21281.

53 Paisley KE, Tomson CR: Calcium phosphate stones during long-term acetazolamide treatment for epilepsy. Postgrad Med J 1999;75:427-428.

54 Betten DP, Bridger DJ, Felton BM: Profound alkalemia secondary to gastric outlet obstruction and acute renal insufficiency. Am J Emerg Med 2013;31:444.e1-3. 